\title{
CARACTERES MORFOANATÔMICOS DE Brachiaria brizantha Submetida À Aplicação de TrineXapac-EThyl ${ }^{1}$
}

\author{
Anatomical Characters of Brachiaria brizantha Submitted to Trinexapac-Ethyl Application
}

\author{
FIALHO, C.M.T. ${ }^{2}$, FERREIRA, E.A. ${ }^{3}$, MEIRA, R.A.S. ${ }^{4}$, SANTOS, J.B. ${ }^{5}$, SILVA, A.A. ${ }^{6}$, FREITAS, \\ F.C.L. ${ }^{7}$, GALON, L. $^{3}$, CONCENÇO, G. ${ }^{8}$, SILVA, A.F. ${ }^{9}$, TIRONI, S.P. ${ }^{9}$ e ROCHA, P.R.R. ${ }^{9}$
}

\begin{abstract}
RESUMO - Objetivou-se com este trabalho avaliar alterações nos caracteres anatômicos e morfológicos da folha (bainha e lâmina) e do caule de Brachiaria brizantha tratada com o regulador de crescimento trinexapac-ethyl. O delineamento experimental utilizado foi o completamente ao acaso, com duas doses do trinexapac-ethyl $\left(0,00\right.$ e 0,75 $\left.\mathrm{kg} \mathrm{ha}^{-1}\right)$ e cinco repetições. Cinquenta dias após a aplicação dos tratamentos, amostras do terço médio da bainha, da lâmina da segunda folha completamente expandida e do entrenó do caule abaixo da inserção da bainha foliar foram coletadas para a determinação de caracteristicas morfológicas, como altura de planta, comprimento e diâmetro de entrenó, comprimento da bainha, comprimento e largura da folha. Para avaliação das características anatômicas, foram realizados cortes transversais da folha e do caule e cortes longitudinais do caule, em micrótomo de mesa, e corados com fuccina e azul de astra preparadas em lâminas semipermanentes. As imagens obtidas foram digitalizadas usando-se microscópio de luz acoplado a câmera digital e conectado a um computador. Para obtenção das medidas de área e medidas lineares foi utilizado o software Image Pro-Plus. Os dados foram submetidos à análise estatística, pelo teste $\mathrm{F}$ a $5 \%$ de probabilidade. O regulador de crescimento promoveu redução do comprimento do limbo foliar, do entrenó, da bainha e da altura de plantas. Por outro lado, no limbo foliar, o trinexapac-ethyl aumentou a espessura da lâmina foliar, da área das células da bainha e da área do mesofilo em B. brizantha.
\end{abstract}

Palavras-chave: anatomia foliar, planta daninha, regulador de crescimento.

\begin{abstract}
The objective of this work was to evaluate changes in the anatomical and morphological characters of leaf (sheath and mesophyll), and stem of Brachiaria brizantha when treated with the plant growth regulator trinexapac-ethyl. The experimental design was completely randomized, with two doses of trinexapac-ethyl $\left(0.00,0.75 \mathrm{~kg} \mathrm{ha}^{-1}\right)$ and five repetitions. Fifty days after treatment application, samples from the middle third of the sheath, blade of the second fully expanded leaf and stem internode below the leaf sheath insertion were collected for the determination of morphological characteristics, such as plant height, internode length and diameter, sheath length and leaflength and width. For evaluation of the anatomical features, transverse cuts of leaves, stem and sheath and longitudinal cuts of the stem were made, in table microtome and stained with fuchsin and astra blue and prepared into semi-permanent slides. The images obtained were scanned using a light microscope coupled to a digital camera and connected to a computer. To obtain area and linear measures, the software Image Pro-Plus was used. The data were subjected to statistical analysis, using the $F$ test at $10 \%$ probability. The growth regulator reduced the length of tho the leaf blade, internode and sheath and also plant height. On the other hand, trinexapac-ethyl increased leaf blade thickness sheath cell and mesophyll areas, providing anatomical and morphological changes in B. brizantha.
\end{abstract}

Keywords: leaf anatomy, weed, growth regulator.

\footnotetext{
1 Recebido para publicação em 12.6.2008 e na forma revisada em 15.5.2009.

2 Eng-à-Agra ., Mestranda do Dep. de Fitotecnia, Universidade Federal de Viçosa - DFT/UFV, 36570-000 Viçosa-MG, <cintiamtfialho@yahoo.com.br>; ${ }^{3}$ Engo-Agro ., D.Sc., Pós-Doutorado, DFT/UFV, <evanderalves@yahoo.com.br>; ${ }^{4}$ Bi[ologa, D.Sc., Professora do Dep. de Biologia Vegetal - DBV/UFV; ${ }^{5}$ Engo-Agro - , D.Sc., Professor da Universidade Federal dos Vales do Jequitinhonha e Mucuri, Faculdade de Ciências Agrárias, Campus II - Rodovia MGT 367 - Km 583, no 5000 Bairro Alto da Jacuba 39100-000 Diamantina-MG; ${ }^{6}$ Engo$^{-}$-Agr ${ }^{\circ}$., D.Sc., Professor Associado do Dep. de Fitotecnia - DFT/UFV, <aasilva@ufv.br>; ${ }^{7}$ Engo-Agro ${ }^{\circ}$, D.Sc., Professor Adjunto do Dep. de Ciências Vegetais, UFERSA; ${ }^{8}$ Engo-Agroo., D.Sc., Pesquisador da Valley, <gconcenco@yahoo.com.br>; ${ }^{9}$ Eng $^{\mathrm{o}}$-Agr ${ }^{\mathrm{o}}$., Doutorando do Dep. de Fitotecnia - DFT/UFV.
} 


\section{INTRODUÇÃO}

Os reguladores de crescimento de plantas têm sido empregados no manejo de inflorescências, no crescimento vegetativo e na qualidade dos gramados (Nielsen, 1992; Dingwall, 1993), reduzindo a emergência, a altura das inflorescências e a frequência de cortes (Freitas et al., 2002). Os reguladores de crescimento são substâncias sintéticas que interferem na biossíntese dos hormônios vegetais (Reddy et al., 1995; Lamas, 2001), podendo afetar o crescimento das plantas e o equilíbrio entre as partes reprodutivas e vegetativas, melhorando a sua eficiência na distribuição de fotoassimilados (Meredith Jr. \& Wels, 1989; Atahyde \& Lamas, 1999). Por esses motivos, esses produtos têm sido utilizados na agricultura, em função de seus efeitos sobre diferentes processos fisiológicos das plantas.

Entre os reguladores de crescimento de plantas, o trinexapac-ethyl tem mostrado efeitos hormonais em diversas espécies pertencentes à família das Poaceae. Esse regulador de crescimento interfere pela inibição da enzima $3 \beta$-hidroxilase, reduzindo o ácido giberélico ativo (GA1) e aumentando o seu precursor biossintético imediato GA20 (Heckman et al., 2002), ocasionando assim a inibição da elongação celular das plantas durante seu estádio vegetativo (Davies, 1987). Os reguladores de crescimento são absorvidos pelas plantas predominantemente pelas folhas e gemas terminais, podendo, todavia, ser absorvidos pelo sistema radicular das plantas. Além de atuarem na morfologia e fisiologia das plantas, os reguladores de crescimento também exercem importante ação nas características anatômicas de órgãos vegetais (Taiz \& Zeiger, 2004).

Em gramado estabelecido com a espécie Axonopus affins tratado com trinexapac-ethyl, aplicado nas doses de 0,0, 0,32 e 0,48 $\mathrm{kg} \mathrm{ha}^{-1}$, Bush \& Porter (1998) verificaram que esse regulador de crescimento, nas doses de 0,32 e $0,48 \mathrm{~kg} \mathrm{ha}^{-1}$, reduziu o crescimento vegetativo e a altura das inflorescências das plantas, evitando cortes, no gramado, pelo período de três e seis semanas, respectivamente. Também Freitas et al. (2002) verificaram que o trinexapac-ethyl, na dose de $0,75 \mathrm{~kg} \mathrm{ha}^{-1}$, reduziu o crescimento vegetativo, a altura e o número de inflorescências da grama-batatais (Paspalum notatum), evitando cortes pelo período de até 12 semanas, sem alterar a qualidade do gramado. Entrenós mais curtos, maior diâmetro de caule e com menor massa seca foram também observados por Zagonel et al. (2002b), quando plantas de trigo foram tratadas com $0,125 \mathrm{~kg} \mathrm{ha}^{-1}$ desse regulador de crescimento. A utilização de produtos químicos fitorreguladores pode ser uma estratégia para reduzir a estatura das plantas e minimizar o problema de acamamento em culturas comerciais. Segundo Lacerda (2004), o trinexapacethyl foi eficaz em reduzir o crescimento das plantas de cana-de-açúcar, no encurtamento dos entrenós e na produção de maior número de gemas por tolete. As doses de trinexapacethyl que ocasionaram maior redução do crescimento e maior número de gemas viáveis por colmo foram de $0,3+0,3 \mathrm{~L} \mathrm{ha}^{-1}$ (duas épocas de aplicação de trinexapac-ethyl), resultando em média de 3,8 gemas por tolete ou 202.667 gemas ha-1 $^{-1}$ com $83 \%$ de viabilidade no campo, em aplicações comerciais.

A espécie Brachiaria brizantha possui ampla adaptação edafoclimática e fácil disseminação, em razão da grande quantidade de sementes produzidas e da dormência destas, facilitando a sua dispersão ao longo do tempo. Embora considerada uma excelente forrageira, pode tornar-se indesejável em áreas de cultivos agrícolas ou naquelas destinadas à produção de forragem para pastejo, ensilagem ou fenação com outras espécies menos competitivas. É a espécie de maior porte entre as braquiárias cultivadas como forrageiras no Brasil. Possui tendência a se inclinar para o solo em consequência de ventos fortes, porém, em razão do geotropismo negativo, volta a desenvolver-se verticalmente quando as plantas se encontram isoladas ou em baixa densidade. O perfilhamento dessa espécie geralmente não é intenso. As folhas são em forma de bainhas fechadas, em geral densamente pilosas, com pelos longos e esbranquiçados (Kissmann, 1997). Em virtude de essa espécie apresentar estatura elevada, o trinexapac-ethyl pode ser utilizado sobre $B$. brizantha, com o objetivo de evitar possiveis acamamentos e, assim, deixar essa espécie, quando usada em pastagens, disponivel como forragem ao gado (Zagonel et al., 2002b). B. brizantha é muito utilizada no sistema de integração agricultura e pecuária, 
principalmente no consórcio com o milho, verificando-se expressiva vantagem competitiva do milho sobre a forrageira (Jakelaitis et al., 2005). O consórcio do milho com a braquiária é possível graças ao diferencial de tempo e espaço no acúmulo de biomassa entre as espécies. Em algumas situações, pesquisadores relatam que a presença da forrageira não alterou a produtividade de grãos de milho; contudo, em alguns casos, é necessário aplicação de subdoses de herbicidas para reduzir o crescimento da forrageira, garantindo pleno desenvolvimento do milho (Jakelaitis et al., 2005).

Neste trabalho objetivou-se avaliar possíveis alterações nos caracteres morfológicos e anatômicos da folha (lâmina e bainha) e do caule de $B$. brizantha submetida à aplicação de trinexapac-ethyl.

\section{MATERIAL E MÉTODOS}

As plantas de $B$. brizantha foram cultivadas em vasos plásticos contendo $5,0 \mathrm{~L}$ de substrato (solo + fertilizantes), em casa de vegetação. Aos 30 dias após a emergência das plantas, fez-se a aplicação do regulador de crescimento trinexapac-ethyl nas doses de 0,00 e $0,75 \mathrm{~kg} \mathrm{ha}^{-1}$, utilizando-se cinco repetições por tratamento. Cinquenta dias após a aplicação do trinexapac-ethyl, quando as plantas se encontravam na fase de emborrachamento, foram coletadas amostras do terço médio da bainha e do limbo da segunda folha completamente expandida e do entrenó do caule, abaixo da inserção da bainha foliar. Nessa ocasião, foram avaliadas as características morfológicas, como altura de planta, comprimento e diâmetro de entrenó, comprimento da bainha e comprimento e largura do limbo foliar.

Para avaliação das características anatômicas, foram realizados cortes transversais da folha, do caule e da bainha e corte longitudinal do caule, em micrótomo de mesa. Os cortes de aproximadamente $30 \mu \mathrm{m}$ de espessura foram clarificados com hipoclorito de sódio a $0,1 \%$ e corados com fuccina e azul de astra. As lâminas semipermanentes foram montadas com gelatina glicerinada e as imagens digitalizadas foram obtidas com microscópio de luz acoplado a câmera digital analógica, conectado a um computador. Para obtenção dos dados da área e medidas lineares na bainha, na folha e no caule, foi utilizado o software Image Pro-Plus.

$\mathrm{Na}$ bainha, as características avaliadas foram: espessura da bainha, diâmetro e distância dos feixes vasculares (medidas lineares); e área das epidermes abaxial e adaxial, das células da bainha, do xilema, do floema e do mesofilo (medidas de área). Na lâmina foliar, tanto no meio como na borda, avaliaram-se a sua espessura, diâmetro do feixe central, distância entre feixes, diâmetro das células buliformes (medidas lineares), área da epiderme abaxial, da epiderme adaxial, das células da bainha, do xilema, do floema e do mesofilo. Na seção transversal do caule, avaliou-se o diâmetro do feixe vascular, do xilema, do floema e do córtex. Nos cortes longitudinais do caule foram avaliados a área da epiderme e o diâmetro do parênquima.

Os dados relativos às características anatômicas e morfológicas foram submetidos à análise estatística, pelo teste $\mathrm{F}$ a $5 \%$ de probabilidade.

\section{RESULTADOS E DISCUSSÃO}

O trinexapac-ethyl promoveu redução do comprimento da lâmina foliar, do entrenó, da bainha e da altura de plantas de $B$. brizantha. Entretanto, não houve modificações na largura da folha e no diâmetro do entrenó (Tabela 1). Em trabalho realizado com trigo, de porte baixo, e com trigo IAPAR-53, de porte médio/alto, Zagonel et al. (2002a, b) também constataram redução substancial da estatura das plantas pelo encurtamento dos entrenós.

Verificaram-se também alterações no desenvolvimento e nas características anatômicas das plantas tratadas. A bainha de $B$. brizantha em seção transversal apresenta aspecto semicircular, onde as margens ficam sobrepostas, envolvendo totalmente o caule, e a região central alargada, conforme descreveu Milby (1971). Nas medidas lineares da bainha (Tabela 2), o regulador de crescimento aumentou a espessura da lâmina foliar em $23 \%$, não se observando diferenças significativas entre os tratamentos em relação ao diâmetro do feixe central e à distância entre feixes. Quanto às medidas de área da bainha (Tabela 3), houve 
redução significativa da epiderme abaxial, das células da bainha, xilema e floema e aumento do mesofilo; dessa forma, constatou-se modificação na proporção de tecidos da bainha foliar, ocasionada pela aplicação do trinexapac-ethyl. No tratamento que não recebeu a aplicação do regulador de crescimento, as proporções de tecidos da bainha, em ordem decrescente, foram: mesofilo, epiderme adaxial, epiderme abaxial, células da bainha do feixe vascular, xilema e floema Já no tratamento que recebeu o produto, os tecidos que ocorreram em maior proporção na seção transversal da bainha da folha foram: mesofilo, epiderme adaxial, epiderme abaxial, células da bainha, floema e xilema.

Para as medidas realizadas em corte longitudinal do caule (Tabela 4), a epiderme aumentou em $14 \%$ para o tratamento com aplicação do regulador de crescimento. Houve um aumento não significativo no diâmetro das células do parênquima. Nas medidas em corte transversal do caule, observou-se elevação do diâmetro do xilema, floema e córtex que receberam aplicação do regulador de crescimento. No entanto, para o diâmetro do feixe não ocorreu diferença estatística entre os tratamentos (Tabela 5).

Tabela 1 - Influência do trinexapac-ethyl sobre as características morfológicas de Brachiaria brizantha

\begin{tabular}{|l|c|c|c|c|c|c|}
\hline \multirow{2}{*}{$\begin{array}{c}\text { Regulador de } \\
\text { crescimento }\end{array}$} & Altura da planta & $\begin{array}{c}\text { Comprimento } \\
\text { da folha }\end{array}$ & $\begin{array}{c}\text { Comprimento } \\
\text { da bainha }\end{array}$ & $\begin{array}{c}\text { Comprimento } \\
\text { do entrenó }\end{array}$ & $\begin{array}{c}\text { Largura da } \\
\text { folha }\end{array}$ & $\begin{array}{c}\text { Diâmetro do } \\
\text { entrenó }\end{array}$ \\
\cline { 2 - 8 } & \multicolumn{7}{|c|}{$(\mathrm{cm})$} \\
\hline Sem trinexapac-ethyl & $59.67 \mathrm{a}$ & $30.60 \mathrm{a}$ & $20.46 \mathrm{a}$ & $15.30 \mathrm{a}$ & $2.00 \mathrm{a}$ & $3.38 \mathrm{a}$ \\
\hline Com trinexapac-ethyl & $43.47 \mathrm{~b}$ & $23.12 \mathrm{~b}$ & $15.30 \mathrm{~b}$ & $8.52 \mathrm{~b}$ & $1.87 \mathrm{a}$ & $3.36 \mathrm{a}$ \\
\hline
\end{tabular}

Médias seguidas pela mesma letra não diferem significativamente pelo teste $F(p<0,05)$.

Tabela 2 - Influência do trinexapac-ethyl sobre as características anatômicas da bainha de Brachiaria brizantha

\begin{tabular}{|l|c|c|c|}
\hline \multirow{2}{*}{$\begin{array}{c}\text { Regulador de } \\
\text { crescimento }\end{array}$} & Espessura da lâmina foliar & Diâmetro do feixe central & Distância entre feixes \\
\cline { 2 - 4 } & \multicolumn{2}{|c|}{$(\mu \mathrm{m})$} & $90,40 \mathrm{a}$ \\
\hline Sem trinexapac-ethyl & $469,50 \mathrm{a}$ & $202,60 \mathrm{a}$ & $85,30 \mathrm{a}$ \\
\hline Com trinexapac-ethyl & $616,00 \mathrm{~b}$ & $205,00 \mathrm{a}$ & $\mathrm{a}$ \\
\hline
\end{tabular}

Médias seguidas pela mesma letra não diferem significativamente pelo teste $F(p<0,05)$.

Tabela 3 - Influência do trinexapac-ethyl sobre as características anatômicas da bainha de Brachiaria brizantha

\begin{tabular}{|l|c|c|c|c|c|c|c|}
\hline \multirow{2}{*}{$\begin{array}{c}\text { Regulador de } \\
\text { crescimento }\end{array}$} & $\begin{array}{c}\text { Epiderme } \\
\text { abaxial }\end{array}$ & $\begin{array}{c}\text { Epiderme } \\
\text { adaxial }\end{array}$ & $\begin{array}{c}\text { Células da } \\
\text { bainha }\end{array}$ & Xilema & \multicolumn{2}{c|}{ Floema } & Mesofilo \\
\cline { 2 - 8 } & \multicolumn{7}{|c|}{$(\mu \mathrm{m})^{2 /}$} \\
\hline Sem trinexapac-ethyl & $5,60 \mathrm{a}$ & $6,05 \mathrm{a}$ & $2,70 \mathrm{a}$ & $0,43 \mathrm{a}$ & $0,41 \mathrm{a}$ & $77.05 \mathrm{~b}$ \\
\hline Com trinexapac-ethyl & $3,95 \mathrm{~b}$ & $5,60 \mathrm{a}$ & $2,00 \mathrm{~b}$ & $0,27 \mathrm{~b}$ & $0,28 \mathrm{~b}$ & $80.96 \mathrm{a}$ \\
\hline
\end{tabular}

Médias seguidas pela mesma letra não diferem significativamente pelo teste $F(p<0,05)$.

Tabela 4 - Influência do trinexapac-ethyl sobre as características anatômicas do caule de Brachiaria brizantha

\begin{tabular}{|l|c|c|c|c|c|c|}
\hline \multirow{2}{*}{$\begin{array}{c}\text { Regulador de } \\
\text { crescimento }\end{array}$} & $\begin{array}{c}\text { Área da } \\
\text { epiderme }\end{array}$ & $\begin{array}{c}\text { Diâmetro do } \\
\text { parênquima }\end{array}$ & Feixe & Xilema & Floema \\
\cline { 2 - 7 } & \multicolumn{2}{|c|}{$\left(\mu \mathrm{m}^{2}\right)^{1 /}$} & \multicolumn{2}{|c|}{$(\mu \mathrm{m})^{1 / /}$} & $33,1 \mathrm{a}$ & $59,1 \mathrm{a}$ \\
\hline Sem trinexapac-ethyl & $174,30 \mathrm{a}$ & $93,60 \mathrm{a}$ & $153,80 \mathrm{a}$ & $118,9 \mathrm{a}$ \\
\hline Com trinexapac-ethyl & $203,00 \mathrm{~b}$ & $96,40 \mathrm{a}$ & $134,15 \mathrm{a}$ & $50,5 \mathrm{~b}$ & $91,45 \mathrm{~b}$ & $166,3 \mathrm{~b}$ \\
\hline
\end{tabular}

Médias seguidas pela mesma letra não diferem significativamente pelo teste $F(p<0,05)$.

/1/ Seção longituginal; ²/ Seção transversal. 
O mesofilo de plantas de B. plantaginea apresenta o parênquima clorofiliano com células poliédricas, grandes, de paredes delgadas, que aumentam de tamanho à medida que se aproximam da região central, não havendo diferenciação entre o parênquima clorofiliano paliçádico e o lacunoso, constituindo, assim, o mesofilo homogêneo (Alves de Brito \& Rodella, 2002). As características relacionadas a medições lineares realizadas no mesofilo (porção central da folha), a espessura da lâmina foliar, o diâmetro do feixe central e a distância entre feixes apresentaram aumento para o tratamento com herbicida (Tabela 5). Alves de Brito \& Deschamps (2001), trabalhando com duas espécies de Panicum, observaram que a distância entre feixes no limbo não mostrou variação. Normalmente, as alterações apresentadas pelas diversas espécies para distância entre os feixes vasculares indicam que esta característica está diretamente ligada ao gênero a que a planta pertence. A menor distância entre os feixes vasculares está relacionada à maior vascularização das folhas, com consequente aumento da capacidade de transporte de fotossintatos e água (Ferreira et al., 2003; Ferreira, 2007).

Na região central da folha, para o tratamento com o trinexapac-ethyl, ocorreu incremento na área das células da bainha, no xilema e no mesofilo de folhas que receberam o produto (Tabela 6). No entanto, somente o aumento na área do mesofilo mostrou diferença significativa. Observou-se redução significativa das epidermes abaxial e adaxial e do floema (Tabela 6). As medidas do xilema e células da bainha não apresentaram diferença significativa para os tratamentos. Como amplamente descrito na literatura, as gramineas tropicais com via fotossintética $\mathrm{C}_{4}$ apresentam anatomia Kranz (Taiz \& Zaiger, 2006). Nesse tipo de estrutura, as células do parênquima clorofiliano dispõem-se radialmente ao redor dos feixes. Internamente a essa coroa de células do mesofilo, encontrase a bainha parenquimática do feixe vascular. Essa bainha, nas espécies em estudo, é simples, ou seja, apresenta apenas uma camada de células, estando de acordo com a descrição feita por Metcalfe (1960) para o gênero Brachiaria. As plantas $\mathrm{C}_{4}$ possuem duas enzimas responsáveis pela fixação do $\mathrm{CO}_{2}$. Essas plantas, além do ciclo de Calvin e Benson, que ocorre em todas as plantas superiores, possuem ainda o ciclo de Hatch e Slack. Essas plantas não apresentam fotorrespiração detectável, logo, não desassimilam o $\mathrm{CO}_{2}$ fixado. A enzima primária de carboxilação é a PEP-carboxilase, localizada nas células do mesofilo foliar, a qual carboxiliza o $\mathrm{CO}_{2}$ absorvido do ar via estômatos, no ácido fosfoenolpirúvico, formando o ácido oxaloacético (AOA). Este AOA é convertido em malato ou aspartato, dependendo da espécie vegetal, e, em seguida, por difusão, é transportado para as células da bainha vascular das folhas, onde esses produtos são descarboxilados, liberando no meio o $\mathrm{CO}_{2}$ e o ácido pirúvico. Este $\mathrm{CO}_{2}$ liberado é novamente fixado, agora pela enzima ribulose 1,5 difosfato carboxilase, ocorrendo o ciclo de Calvin e Benson; o ácido pirúvico, por difusão, retorna às células do mesofilo, onde é fosforilado, consumindo 2 ATPs, regenerando a enzima PEP-carboxilase e recomeçando o ciclo. Na porção central da folha foi observada também modificação na proporção de tecidos. No tratamento sem a aplicação do produto, observou-se maior proporção de floema em relação ao xilema; nas plantas tratadas com herbicida essa relação entre floema e xilema foi inversa (Tabela 6).

Nas características relacionadas a medidas lineares da folha (porção lateral), o herbicida provocou aumento significativo da espessura da lâmina foliar em $18 \%$ e aumentou o diâmetro do feixe central, bem como a distância entre feixes (Tabela 7). Para características relacionadas a medidas de área da folha, não foi observada diferença significativa nos tratamentos, exceto para as células da bainha do feixe vascular, que apresentaram aumento com a aplicação do produto (Tabela 8). A aplicação de SADH em macieiras jovens do cultivar Golden Delicious e York Imperial provocou aumento das células do tecido paliçádico; o parênquima lacunoso apresentou-se mais frouxo, o que levou ao espessamento foliar e aumento da superficie das folhas (Halfacre \& Barden, 1968). As principais alterações dos retardadores de crescimento incluem reduzir o consumo de água, retardar a senescência, aumentar a resistência aos estresses ambientais e aumentar a concentração de clorofila nas folhas (Davis et al., 1988; Grossmann, 1990).

Planta Daninha, Viçosa-MG, v. 27, n. 3, p. 533-539, 2009 
Tabela 5 - Influência do trinexapac-ethyl sobre as características anatômicas da folha de Brachiaria brizantha (centro da folha)

\begin{tabular}{|l|c|c|c|c|}
\hline \multirow{2}{*}{$\begin{array}{c}\text { Regulador de } \\
\text { crescimento }\end{array}$} & $\begin{array}{c}\text { Espessura da lâmina } \\
\text { foliar }\end{array}$ & $\begin{array}{c}\text { Diâmetro do } \\
\text { feixe central }\end{array}$ & $\begin{array}{c}\text { Distância entre } \\
\text { feixes }\end{array}$ & $\begin{array}{c}\text { Diâmetro das células } \\
\text { buliformes }\end{array}$ \\
\cline { 2 - 5 } & \multicolumn{3}{|c|}{$(\mu \mathrm{m})$} \\
\hline Sem trinexapac-ethyl & $192,5 \mathrm{a}$ & $164,9 \mathrm{a}$ & $70,20 \mathrm{a}$ & $35,90 \mathrm{a}$ \\
\hline Com trinexapac-ethyl & $236,3 \mathrm{~b}$ & $181,9 \mathrm{~b}$ & $76,40 \mathrm{~b}$ & $38,95 \mathrm{a}$ \\
\hline
\end{tabular}

Médias seguidas pela mesma letra não diferem significativamente pelo teste $F(p<0,05)$.

Tabela 6 - Influência do trinexapac-ethyl sobre as características anatômicas da folha de Brachiaria brizantha (centro da folha)

\begin{tabular}{|l|c|c|c|c|c|c|c|}
\hline \multirow{2}{*}{$\begin{array}{c}\text { Regulador de } \\
\text { crescimento }\end{array}$} & $\begin{array}{c}\text { Epiderme } \\
\text { abaxial }\end{array}$ & $\begin{array}{c}\text { Epiderme } \\
\text { adaxial }\end{array}$ & $\begin{array}{c}\text { Células da } \\
\text { bainha }\end{array}$ & Xilema & \multicolumn{2}{|c|}{ Floema } & Mesofilo \\
\cline { 2 - 8 } & \multicolumn{7}{|c|}{$\left(\mu \mathrm{m}^{2}\right)$} \\
\hline Sem trinexapac-ethyl & $17,15 \mathrm{a}$ & $11,65 \mathrm{a}$ & $4,30 \mathrm{a}$ & $0,25 \mathrm{a}$ & $0,29 \mathrm{a}$ & $63,28 \mathrm{~b}$ \\
\hline Com trinexapac-ethyl & $15,30 \mathrm{~b}$ & $8,70 \mathrm{~b}$ & $4,40 \mathrm{a}$ & $0,28 \mathrm{a}$ & $0,26 \mathrm{~b}$ & $67,99 \mathrm{a}$ \\
\hline
\end{tabular}

Médias seguidas pela mesma letra não diferem significativamente pelo teste $F(p<0,05)$.

Tabela 7 - Influência do trinexapac-ethyl sobre as características anatômicas da folha de Brachiaria brizantha (borda da folha)

\begin{tabular}{|l|c|c|c|c|}
\hline \multirow{2}{*}{$\begin{array}{c}\text { Regulador de } \\
\text { crescimento }\end{array}$} & $\begin{array}{c}\text { Espessura da lâmina } \\
\text { foliar }\end{array}$ & $\begin{array}{c}\text { Diâmetro do } \\
\text { feixe central }\end{array}$ & $\begin{array}{c}\text { Distância entre } \\
\text { feixes }\end{array}$ & $\begin{array}{c}\text { Diâmetro das células } \\
\text { buliformes }\end{array}$ \\
\cline { 2 - 5 } & \multicolumn{3}{|c|}{$(\mu \mathrm{m})$} \\
\hline Sem trinexapac-ethyl & $269,60 \mathrm{a}$ & $225,70 \mathrm{a}$ & $89,65 \mathrm{a}$ & $44,08 \mathrm{a}$ \\
\hline Com trinexapac-ethyl & $306,15 \mathrm{~b}$ & $249,61 \mathrm{~b}$ & $102,99 \mathrm{~b}$ & $41,95 \mathrm{a}$ \\
\hline
\end{tabular}

Médias seguidas pela mesma letra não diferem significativamente pelo teste $F(p<0,05)$.

Tabela 8 - Influência do trinexapac-ethyl sobre as características anatômicas da folha de Brachiaria brizantha (borda da folha)

\begin{tabular}{|l|c|c|c|c|c|c|c|}
\hline \multirow{2}{*}{$\begin{array}{c}\text { Regulador de } \\
\text { crescimento }\end{array}$} & $\begin{array}{c}\text { Epiderme } \\
\text { abaxial }\end{array}$ & $\begin{array}{c}\text { Epiderme } \\
\text { adaxial }\end{array}$ & $\begin{array}{c}\text { Células da } \\
\text { bainha }\end{array}$ & Xilema & \multicolumn{2}{|c|}{ Floema } & Mesófilo \\
\cline { 2 - 8 } & \multicolumn{7}{|c|}{$\left(\mu \mathrm{m}^{2}\right)$} \\
\hline Sem trinexapac-ethyl & $11,72 \mathrm{a}$ & $8,92 \mathrm{a}$ & $3,91 \mathrm{a}$ & $0,15 \mathrm{a}$ & $0,30 \mathrm{a}$ & $71.38 \mathrm{a}$ \\
\hline Com trinexapac-ethyl & $11,60 \mathrm{a}$ & $8,53 \mathrm{a}$ & $4,30 \mathrm{~b}$ & $0,13 \mathrm{a}$ & $0,32 \mathrm{a}$ & $71.47 \mathrm{a}$ \\
\hline
\end{tabular}

Médias seguidas pela mesma letra não diferem significativamente pelo teste $F(p<0,05)$.

Concluiu-se que o trinexapac-ethyl promoveu alterações marcantes na morfologia e na anatomia da folha e do caule de $B$. brizantha. As plantas submetidas ao tratamento com o regulador de crescimento apresentaram redução significativa em altura, comprimento da folha, bainha e entrenó. Com relação às alterações anatômicas, o regulador de crescimento aumentou a espessura da lâmina foliar, da área das células da bainha e da área do mesofilo em $B$. brizantha.

\section{AGRADECIMENTOS}

Os autores agradecem ao CNPq e à FAPEMIG, pelo apoio financeiro.

\section{LITERATURA CITADA}

ALVES DE BRITO, C. J. F., RODELLA, R.A., DESCHAMPS, F.C. et al. Anatomia quantitativa e degradação in vitro de tecidos em cultivares de capim-elefante

(Pennisetum purpureum Schumach.). Rev. Bras. Zootec.,

v. 28, n. 2 , p. $223-229,1999$ 
ALVES DE BRITO, C. J. F.; DESCHAMPS, F. Caracterização anatômica em diferentes frações de cultivares de capim-elefante (Pennisetum purpureum Schumach.) $\mathbf{R}$.

Bras. Zootec., v. 30, n. 5, p. 1409-1417, 2001

ALVES DE BRITO, C. J. F.; RODELLA, A. Caracterização morfo-anatômica da folha e do caule de Brachiaria brizantha (Hochst. exA. Rich.) Stapf e B. humidicola (Rendle) Schweick. (Poaceae). R. Bras. Bot., v. 25, n. 2, p. 519-528, 2002.

ATAHYDE, M. L. F.; LAMAS, F. M. Aplicação de cloreto de mepiquat no algodoeiro. Pesq. Agropec. Bras., v. 34, n. 3, p. $369-375,1999$.

BUSH, E. W., PORTER, W. C. Controlling growth of common carpetgrass using selected plant growth regulators.

HortScience, v. 4, n. 33, p. 704-706, 1998.

DAVIES, P. J. The plant hormones: their nature, occorrence, and functions. In: DAVIES, P.J. Plant hormones and their role in plant growth and development. Dordrecth: Kluwer Academic, 1987. p. 1-23.

DAVIS, T. D.; STEFFENS, G. L; SANKHLA, N. Triazole plant growth regulators. Hortic. Rev., v. 10, n. 1, p. 63-105, 1988.

DINGWALL, J. G. Key chemical inputs to new herbicides: Intermediates processes, an mechanistic investigations. Pest. Sci., v. 41, n. 2, p. 259-267, 1993.

FERREIRA, E. A. et al. Anatomia quantitativa da lâmina foliar de genótipos de cana-de-açúcar. Planta Daninha, v. 25, n. 1, p. 25-34, 2007

FERREIRA, E. A. et al. Estudos anatômicos de folhas de espécies de plantas daninhas de grande ocorrência no Brasil: IV - Amaranthus deflexus, Amaranthus spinosus, Alternanthera tenella e Euphorbia heterophylla. Planta Daninha, v. 21, n. 2, p. 263-271, 2003.

FREITAS, F. C. L. et al. Efeitos do trinexapac-ethyl sobre o crescimento e florescimento da grama-batatais. Planta Daninha, v. 20, n. 3, p. 477-486, 2002.

GROSSMANN, K. Plant growth retardants as tools in physiological research. Physiol. Plant., v. 78, n. 3, p. 640-648, 1990.

LACERDA, A. L. S. Avaliação do trinexapac-ethyl sobre o crescimento de cana-de-açúcar. 2004. 6 p. Disponível em: $<$ http://www.cori.unicamp.br/centenario2008/completos $>$ Acesso em: 11 jun. 2008.
HALFACRE, R. G.; BARDEN, J. A. Anatomical responses of apple leaf and stem tissue to succinic acid 2, 2dimethylhydrazida (Alar). Proc. Am. Soc. Hortic. Sci., v. 93, n. 1, p. $25-32,1968$

HECKMAN, N. L. et al. Influence of trinexapac-ethyl on respiration of isolated wheat mitochondria. Crop Sci., v. 42, n. 2, p. 423-427, 2002.

JAKELAITIS, A. S. et al. Influência de herbicidas e de sistemas de semeadura de Brachiaria brizantha consorciada com milho. Planta Daninha, v. 23, n. 1, p. $59-69,2005$

KISSMANN, K. G;; GROTH, D. Plantas infestantes e nocivas. 2.ed. São Paulo: BASF, 1997. Tomo I. 825 p.

LAMAS, F. M. Regulador de crescimento na cultura do algodoeiro: comparação entre produtos e formas de fracionamento de doses. In: CONGRESSO BRASILEIRO DE ALGODÃO, 3., 2001. Campo Grande. Anais... Campina Grande: Embrapa Algodão, 2001. p. 514-518.

MEREDITH Jr., W. R.; WELL, R. Potential for increasing cotton yields through enchanced partitioning to reproductive strutures. Crop Sci., v. 29, n. 3, p. 636-639, 1989.

METCALFE, C. R. Anatomy of monocotyledons. Gramineae. Oxford: Clarendon Press, 1960. v. 1. 345 p.

MILBY, T. H. The leaf anatomy of buffalo grass, Buchloë dactyloides (Nutt.) Engelm. Bot. Gaz, v. 132, n. 3, p. 308-313, 1971.

NIELSEN, S. Pricing chellenges. Grounds Maint., n. 11, p. $12-16,1992$

REDDY, K. R. et al. Developing and validating a model for plant growth regulator. Agron. J., v. 87, n. 6, p. 1100-1105, 1995.

TAIZ, L.; ZEIGER, E. Plant physiology. Sunderland: Sinauer, 2004. 705 p.

ZAGONEL, J. et al. Doses de nitrogênio e densidades de plantas com e sem um regulador de crescimento afetando o trigo, cultivar OR-1. Ci. Rural, v. 32, n. 1, p. 25-29, 2002a.

ZAGONEL, J.; VENANCIO, W. S.; KUNZ, R. P. Efeito de regulador de crescimento na cultura do trigo submetido a diferentes doses de nitrogênio e densidade de plantas.

Planta Daninha, v. 20, n. 3, p. 471-476, 2002 b. 